\title{
Liminalni identiteti i transnacionalni prostori u doba pandemije bolesti COVID-19
}

\author{
Franka Zlatić \\ Sveučilište u Nottinghamu, Škola sociologije i socijalne politike, Ujedinjeno \\ Kraljevstvo \\ e-mail:franka.zlatic@nottingham.ac.uk
}

SAŽETAK Ovaj je rad sažetak doktorskog istraživanja na temu individualne migracije u Ujedinjeno Kraljevstvo. Teorijski okvir istraživanja oslanja se na metodološki denacionalizam te alternativna poimanja prostora i mjesta u migracijskom kontekstu, koja su opisana u prvome dijelu rada. U drugome dijelu rada opisujem utjecaj pandemije bolesti COVID-19 te na koji je način metodologija projekta revidirana i prilagođena za izvođenje u online okruženju. Kroz ovaj rad opisujem kako je to utjecalo na daljnje planiranje terenskoga rada te način na koji su te promjene u skladu s metodološkim okvirom projekta. Zaključno, nude se alternative kvalitativnim metodama u migracijskim istraživanjima te potencijalne prednosti koje nudi terenski rad u online okruženju.

Ključne riječi: transnacionalizam, liminalnost, multilokalna etnografija, migracije, transnacionalni društveni prostori, COVID-19. 


\section{Uvod}

Every immigrant enters the destination state as a foreigner, excluded from the circle of receiving society citizens (Waldinger i Catron, 2016.:47) ${ }^{1}$

Ovaj je citat potaknuo moja razmišljanja o suvremenoj migraciji koja su naknadno dovela do moga doktorskog istraživanja. Jednostavnim riječima Stevena Vertoveca (2007.), više ljudi sada migrira s više polazišnih mjesta, ali jedna od najvećih razlika $\mathrm{u}$ usporedbi $s$ prijašnjim tipovima migracija jest da rast transnacionalnih zajednica nije vezan niti uz mjesta odredišta niti uz mjesta polazišta migranata (Vertovec i Cohen, 1999.:xiii). Doktorsko je istraživanje zamišljeno kao etnografska studija s kvalitativnim metodama, na koje su utjecale mjere povezane s pandemijom koronavirusa. Istraživanje multietničkih individualnih migranata zahtijeva alternativne pristupe koji objedinjuju transnacionalne i tranzitne populacije te integraciju s fluidnim i multiraznolikim (vlastiti prijevod, svi ostali prijevodi, osim ako nije drugačije naznačeno, također su vlastiti; Vertovec, 2007.) zajednicama. Cilj je ovoga rada skrenuti pozornost na moguće posljedice koje je pandemija imala na migrante, ali i na trenutačna istraživanja o migraciji. Ograničeno kretanje i socijalna distanca znatno su utjecali na poimanje prostora kakav smo dosad poznavali, posebice kada se radi o transnacionalnim društvenim prostorima. Daljnji teorijski okvir bit će objašnjen u prvome dijelu rada, $s$ fokusom na koncepte mjesta, prostora i doma, dok će se drugi dio bazirati na implikacijama i metodološkim promjenama uzrokovanim koronavirusom. Iako se istraživanje u originalnom izdanju provodi na engleskom jeziku, za potrebe pisanja ovoga rada dosadašnji rad i doprinos projektu bit će prevedeni na hrvatski jezik.

\section{Teorijski okvir istraživanja}

Oslanjajući se na nekoliko teorijskih pravaca usko vezanih uz područje migracija, ovaj projekt objedinjuje teorije transnacionalizma i transnacionalnih praksi bivanja i pripadanja (Levitt i Glick Schiller, 2004.), etničkih i nacionalnih identiteta, liminalnosti, integracije, materijalne kulture te koncepte mjesta i doma. Cilj ovoga doktorskog rada jest ispitati odnos između inkorporacije individualnih migranata u zemlji useljenja (u ovom slučaju Ujedinjeno Kraljevstvo) i održavanja transnacionalnih veza, istovremeno naglašavajući mobilnost i fleksibilnost identiteta migranata. Istraživanje želi doprinijeti boljem razumijevanju subjekata specifično u liminalnoj fazi migracije, koja zajedno uz odvajanje i agregaciju čini proces liminalnih obreda (Turner, 1970.). Nastavljajući na tradicionalnu upotrebu pojma liminalnosti (van Gennep, 1960.; Turner, 1970.) te pružajući istovremeno suvremenu interpretaciju pojma, Szakolczai (2014.) predlaže da svaka od prethodno spomenutih te inicijalno privremenih faza

1 „Svaki imigrant ulazi u zemlju odredišta kao stranac, isključen iz kruga domicilnog stanovništva“ (Waldinger i Catron, 2016.:47) 
može postati trajna kada subjekt ne nastavi na iduću fazu, nego „zaglavi“ u jednoj dugotrajno. U tom slučaju to „zamrzavanje“ (Szakolczai, 2014.) izaziva trajnu liminalnost identiteta, putem kojega se naglašava osjećaj betwixt and between ${ }^{2}$ (Turner, 1970.). S obzirom na to da je u središtu fokusa liminalnost identiteta individualnoga migranta u UK-u, pod pojmom individualni migranti podrazumijevaju se intencionalni i dobrovoljni migranti koji su samostalno doselili u UK u posljednjih deset godina. Sudionici mogu, ali i ne moraju biti građani EU-a, u trenutku provođenja intervjua mogu živjeti s osobama iz svoje matične zemlje, ali je uvjet da su te osobe doselile nakon njihova inicijalnog preseljenja u UK. Sudionici istraživanja mogu, ali i ne moraju završiti prethodno obrazovanje u UK-u. Fokus je na migrantima koji su svoj home away from home ${ }^{3}$ konstruirali sami, ostvarujući nove kontakte i kulturne navike u UK-u i održavajući kontakte i tradicije iz svoje zemlje porijekla.

Važno je napomenuti i da se ovaj rad oslanja na metodološki denacionalizam (Anderson, 2019.; Kivisto, 2001.) i koncept multiraznolikosti (Vertovec, 2007.). Multiraznolikost (engl. super-diversity) i metodološki denacionalizam u ovom istraživanju predlažem kao alternativu postojećim metodologijama istraživanja migracija i kako bismo popunili trenutačnu post-multikulturalnu teorijsku prazninu (Grzymala-Kazlowska i Phillimore, 2018.:180) nastalu temeljenjem dosadašnjih istraživanja na jednoj nacionalnoj, etničkoj ili religijskoj zajednici. Ovaj se projekt na neki način može poistovjetiti s pokretom otpora protiv metodološkoga nacionalizma (Braidotti, 2011.:7), a kasnije će biti objašnjeno kako je pandemija bolesti COVID-19 imala donekle pozitivan efekt u obrazloženju i opravdanju takva pristupa. Multiraznolikost je, $s$ druge strane, percipirana kao dolazak mnogih individualnih migranata iz mnogih zemalja i odražava posljedičnu fragmentaciju ustaljenja i integracije (Grzymala-Kazlowska i Phillimore, 2018.). Također, predlažem preusmjerenje interesa sa singularnoga pojedinačnog lokaliteta kao polazišne jedinice u etnografskome istraživanju na višestruko lokaliziranu etnografiju (Falzon, 2009.) te koncepte transmjesta i translokalnosti (Rodman, 1992.), koji objedinjuju ideje geografske lokacije (prostorna distribucija socioekonomske aktivnosti), osjećaja i pripadnosti mjestu te lokalitet i kontekst određenoga mjesta, o čemu će se više govoriti u nastavku ovoga rada.

Sličnu je problematiku vezanu uz „etničku prizmu “ prepoznala i Povrzanović Frykman (2010.), kao i Glick Schiller (2008.), naglašavajući kako takav etnički, odnosno nacionalni pristup „dominira istraživanjem međunarodnih migracija“ (Povrzanović Frykman, 2010.:40) i time ograničava šire mogućnosti razumijevanja fenomena. Nacionalni pristup, kao i nacionalni identiteti „kada su nametnuti kao analitička kategorija od teoretičara nacionalizma, ostavljaju malo mjesta za raspravu o tome na koji se

2 Engl. dosl. „između i između“, preneseno značenje za „ni jedno ni drugo“.

3 Engl. dosl. „dom udaljen od doma“; mjesto ili lokacija u kojoj netko ne mora prebivati stalno, ali se ondje osjeća kao kod kuće. 
način identiteti kroje i reproduciraju u odnosu na prostor i vrijeme“ (Bell, 2003.:64). Naspram kolektivnoga pristupa zajednicama dijaspore ovim se istraživanjem želi skrenuti pozornost na ,individualnost migracije, odnosno, individualne migrante i njihove priče" (Campos-Delgado, 2018.:494) kako bismo mogli dublje razumjeti raznolikost profila i pozadina koje se spajaju u tim pričama (Campos-Delgado, 2018.).

\subsection{Razumijevanje mjesta/prostora}

Polazeći od binarne opozicije prostora i mjesta, ovim se radom želi skrenuti pozornost na njihovu arbitrarnu vezu, koja nije nužno usko vezana uz geografsku lokaciju. Dok je prostor često nedefiniran i generaliziran pojam, „mjesto je definirano kao kulturalno i intimno s naglaskom na nastanjenje i osjećaj kao kod kuće“ (Low 2016.:21). Takve definicije mjesta čine suprotnost apstraktnosti prostora još većom i opisuju prostor kao nešto nepoznato i nedefinirano. U odnosu prostora i mjesta vrlo je koristan Heideggerov (2010.) koncept prebivališta (engl. dwelling), u smislu opisivanja domestikacije prostora. Prebivalište u Heideggerovu kontekstu može biti shvaćeno kao djelovanje, s obzirom na to da se odnosi na proces „namjerne modifikacije okoliša“ (Low, 2016.:17). Kao jedna od osnovnih ljudskih potreba da se upozna s okolišem u kojem obitava, prebivalište se opisuje kao „zapletenost ljudskih odnosa sa svijetom“ (Heidegger, 2010., u Low, 2016.:17). Drugim riječima, kroz koncept prebivališta prostor postaje mjestom, poprištem identiteta i značenja (Augé, 1995.).

Nastavno na opisane koncepte prostora i mjesta, a u relaciji s migracijskim istraživanjima, predlažem da bilo koji prostor može postati mjesto koje je utjelovljeno mnogim simbolima, ali da migrant inicijalno putuje iz mjesta u prostor, iz poznatoga u nepoznato, s mogućnošću transformiranja toga novonastanjenoga prostora u mjesto uz migrantovu namjeru i ambiciju za prebivalištem. Nadalje, Appadurai (1996.) polazi od slične pretpostavke da destabilizacija nastala u transnacionalnim prostorima može uzrokovati promjene u značenju lokaliteta: „[...] transformacija prostora u mjesta zahtijeva svjesni trenutak, koji se posljedično zapamtiti kao rutina“ (Appadurai, 1996.:213), koji zatim omogućava migrantima višestruka relociranja, višestruke integracije i višestruke transformacije prostora u mjesto. Naravno, takav proces često uključuje i osjećaj nelagode i tjeskobe (Appadurai, 1996.), koji može izazvati prethodno spomenutu liminalnost identiteta (vidi: Thomassen 2014.; Turner, 1970.; Beech, 2011.), odnosno osjećaj bivanja između i nečega što Turner (1970.) naziva progresivnim stanjem. Nastavno na liminalnost identiteta, mnogi teoretičari (Bhabha, 1994.; Appadurai, 1995.) zagovaraju da identitet ne mora nužno biti vezan uz fizičku lokaciju, već „kada postane deteritorijaliziran, gotovo neizbježno postaje lociran između mjesta, umjesto vezan uz pojedina mjesta ili domovine“ (Tilley, 2006.:13). Identitet je, u kontekstu migracije, „rezultat raznih interakcija koje se događaju u prostorima čije granice nisu jasno definirane" (Mouffe, 1994.:110) te je on uvijek konstituiran u odnosu na ono „drugo“ koje čini njegovu vanjštinu (Mouffe, 1994.:107), što dodatno prikazuje arbitrarnost i kompleksnost koncepta prostora i identiteta u migracijama. 
Nadovezujući teorijski okvir mjesta i prostora na prethodno spomenut koncept multiraznolikosti (Vertovec, 2007.), ovaj je rad prilika da se multilokalnost i multivokalnost aktera u migraciji pokažu kao dostojna alternativa postojećem metodološkom nacionalizmu i istraživanjima baziranim u velikim melting pot $t^{4}$ gradovima. Kao što je prethodno spomenuto, multiraznolikost ne bi trebala biti bazirana na tradicionalnim monoetničkim i mononacionalnim pristupima. Rodman (1992.) predlaže novi pristup lokalitetima u radu na terenu jer također smatra da su mjesta, odnosno prostori društveno konstruirani. Kao svojevrsna nadogradnja na literaturu o zamišljenim zajednicama (Anderson, 2016.) i zamišljenim krajolicima (Appadurai, 1990.), Rodman (1992.:642) razmatra mjesta kao dvostruka: jedan pogled drži da su mjesta društveno konstruirana doživljena iskustva, dok drugi pogled opisuje mjesta kao antropološki konstrukt za određivanje lokaliteta terenskoga rada. Dok je za većinu terenskih radova doista potrebna geografska lokacija istraživanja, odnosno lokalitet istraživanja, u projektima koji se oslanjaju na metodološki denacionalizam i na suvremene migracijske i transnacionalne prakse lokalitet u smislu geografije može (i katkad treba) postati sekundaran. Umjesto prostornoga stvaranja mjesta predlažem konceptualno i konstruirano poimanje mjesta kako bi se približilo i bolje objasnilo suvremene posljedice individualne migracije, kao što je primjerice fenomen multiraznolikosti. Odmicanje od geografski definiranoga lokaliteta implicira razumijevanje mjesta kao življenoga, što uključuje ne samo fizičko mjesto bivanja već i društveni prostor i vrijednosti vezane uz oboje prethodno (Berdoulay, 1989.). Stvaranje je mjesta stoga povezano uz prostorne i društvene odnose i vrijednosti individue, umjesto pretpostavke da osoba naseljava unaprijed uvjetovano fizičko mjesto jer, riječima Lefebvrea (1991.:154), „prostor nikad [nije] prazan: on uvijek utjelovljuje značenje“.

Naravno, takvo arbitrarno shvaćanje prostora komplicira metodološke implikacije pojedinog istraživanja jer daljnje varijable moraju biti detaljnije opisane kako bi istraživanje imalo značenje u epistemološkom kontekstu. Drugim riječima, iako bi se opisano shvaćanje prostora i mjesta moglo primijeniti bilo gdje u svijetu, nasumična regrutacija sudionika u istraživanju ne bi imala smisla osim ako ostali uvjeti vezani uz njihova transnacionalna iskustva nisu u najmanju ruku podjednaki. U tom smislu, profil migranta/sudionika mora biti opisan u detalje, posebice vezano uz socioekonomske faktore koji utječu na sveukupno migracijsko iskustvo. U smislu geografske pozicije, teorija društveno konstruiranog i arbitrarnog lokaliteta daje veću slobodu po pitanju određivanja lokaliteta, ali taj lokalitet i dalje mora reflektirati jednake mogućnosti za migrante i jednake socioekonomske karakteristike. Zaključno, umjesto da se pojedino istraživanje provodi u multikulturalnom i potencijalno kozmopolitskom Londonu, uz ovakvu teorijsku pozadinu moguće je proširiti istraživanje na ostatak Engleske ili možda čak na cijelo Ujedinjeno Kraljevstvo. Svako daljnje proširenje uzrokovalo bi daljnju razradu ostalih faktora vezanih uz profil sudionika i karakteristike interesnog područja, ali takva istraživanja uvelike doprinose i vrlo relevantnim radovima o transnacionalizmu i migraciji (vidi Favell, 2008.).

${ }^{4}$ Engl. dosl. „lonac za taljenje“; metafora za homogenizaciju heterogenog društva ili zajednice. 
Opisana devijacija od ustaljenih i čestih istraživanja u velikim multikulturalnim gradovima može biti sagledana i iz perspektive diskusija o centru - periferiji / centru - marginama (Andrucki i Dickinson, 2015.), iz kojih se može iščitati da su migranti koji su se nastanili u manjim gradovima ili čak selima manje zanimljivi od onih koji su odabrali melting pot grad, kao što je primjerice London. To, dakako, ne znači da su migranti koji su doselili u London isključeni iz ovog istraživanja, nego se želi skrenuti pažnju na to da suvremena migracija ne mora slijediti utabane putove i prethodne uzorke migracije u glavne gradove i velike gradove Zapada. Naprotiv, migracijski pokreti često uključuju nestalnosti, zaobilazne puteve i višestruke destinacije (Yeoh i sur. 2005., u Andrucki i Dickinson, 2015.:204). Da bi se takva metodološka promjena uspješno primijenila, Marcus (1989.) zagovara sljedeće promjene: (1) primjenu multilokalne etnografije, (2) pažnju usmjerenu na mreže kompleksnih povezanosti i njihovih simultanih i recipročnih efekata i (3) želju za kontekstualiziranjem istraživanih povezanosti u smislu šire slike i njihovih posljedica (Smith, 2005.:5). Slično je stajalište opisano i u razumijevanju konteksta doma; uzimajući u obzir prijedlog da je „stvaranje doma“ zapravo stvaranje „osjećaja sigurnosti doma“ (Hage, 1997.:2), dom postaje afektivni konstrukt, radije nego „mjesto porijekla“ $\mathrm{i}$ „puštanje korijenja“. $\mathrm{U}$ nastavku ću objasniti stajalište o domu u migracijama te kako dom, kao i koncept mjesta, može biti rezultat društvene odnosno individualne konstrukcije.

\subsection{Koncept doma u transnacionalnim prostorima}

Jedna od najčešćih pitanja i diskusija u migracijskim istraživanjima ona su o domu. Što znači vratiti se doma? Što znači napustiti dom? Gdje je dom i kako kuća postaje dom? Do koje je mjere dom vezan uz geografsku lokaciju i fizičku kuću? Često se pretpostavlja da osjećaj pripadanja ili mjesta donosi stabilnost (Sarup, 1994.:94). Ali što čini mjesto domom? Nerijetko su to „sretna i ugodna sjećanja, intimne situacije, mjesto topline i zaštitničke sigurnosti uz roditelje, braću i sestre, voljene ljude" (Sarup, 1994.:94). Dakako, koncept i ideja doma nisu jednaki u svim kulturama, ali čini se da je ideja doma usko povezana s konceptom identiteta i pričom koju pričamo sebi i o sebi (Sarup, 1994.:95).

Komplicirana veza između migranata i njihovih domova zapravo je kvintesencijalna karakteristika transnacionalne migracije (Al-Ali i Koser, 2002.), postajući neizbježan koncept u transnacionalnim praksama. Za mnoge su migrante materijalne i zamišljene geografije doma višestruke i dvosmislene te razotkrivaju privrženost prema nekoliko mjesta i načine na koji je dom oblikovan uspomenama i svakodnevnim životom u sadašnjosti (Blunt i Dowling, 2006.:202). Gradnja je doma u tom smislu ,izgradnja osjećaja kao kod kuće" (Hage, 1997.:2) te asocirana uz četiri osjećaja s kojima se migranti mogu susresti: sigurnost, familijarnost (prisnost), zajedništvo i osjećaj ili mogućnost nade (Hage, 1997.:2). Uspomene i sjećanja usko su povezani s migracijama jer imaju ulogu čuvanja i ostvarivanja novih formi društvenih odnosa i odnosa prema prostoru (Tošić i Palmberger, 2016.:1). 
Moramo „revidirati pretpostavku da je 'dom', u migraciji, jednostavno nešto što 'puštamo za sobom"“ (Ahmed i sur. 2003.:8). U procesu „stvaranja doma“ mnoga druga mjesta također mogu označavati "dom" u odnosu na to kako se identiteti mijenjaju i pregovaraju (Blunt i Dowling, 2002.:218). Iz te perspektive, migracijska istraživanja ne bi trebala sva biti temeljena na istoj zemlji porijekla kao „polazišnoj točki identifikacije za studije dijaspore" (Blunt i Dowling, 2002:218) i istoj zemlji odredišta kao skupu novih identifikacija s kojima se migranti trebaju angažirati nakon dolaska. Dom je kontinuirani proces produkcije i reprodukcije vrijednosti koji nikad nije potpun ni završen (Gedalof, 2003.). Važno je napomenuti da je afektivnost doma usko vezana uz temporalnu dimenziju doma, uz prošlost, sadašnjost i budućnost. Tako je dom kod migranata istovremeno nešto iz prošlosti i nešto što izaziva nostalgiju, dok jednako tako može biti prisutan u sadašnjosti kroz rekonstrukciju doma u zemlji odredišta. Pritom doma i daleko (ovdje i ondje) nisu nužno suprotnosti. Doma je „negdje drugdje“, postaje nemogućnost i neophodnost subjektove budućnosti, tamo gdje nitko ne stiže, ali svi idu u tom smjeru, naspram prošlosti koja veže subjekt uz dano i određeno mjesto (Lems, 2018.).

U knjizi Uprootings/Regroundings, Ahmed i sur. (2003.) polaze od pretpostavke da dom nije nešto što je usko vezano uz geografska obilježja migracije, već fokusiraju koncept doma kao skup iskustava, povijesti i postavki u odnosu na institucionalne strukture. Drugim riječima, dom nije fizička kuća koju su migranti ostavili za sobom, nego autori skreću pozornost na to kako su migracijska relociranja prikazana - simbolički, afektivno i materijalno - u odnosu na dom i osjećaj doma (Ahmed i sur., 2009.:2). O vezi doma i identiteta Blunt i Dowling (2006.:256) naglašavaju da „[d]om kao mjesto i kao prostorni imaginarij pomaže u konstituiranju identiteta, pri čemu je shvaćanje jastva vezano i stvoreno kroz življena i metaforička iskustva doma“. Dom u tom smislu može predstavljati sigurno utočište i simboličku vrijednost zaštite od invazije/razlike (Massey, 2005.:6) koje naglašavaju Drugost (vidi: Anderson, 2016.; Said, 1995.) migranata.

\section{Utjecaj pandemije na koncept doma i lokaliteta u migracijskim temama}

Prethodni opis i diskusija o konceptu doma, posebice u kontekstu migracija, poprimaju drukčiji oblik kada su u pitanju okolnosti koje nisu potpuno u kontroli aktera, odnosno stanovnika pojedinog doma. Nedavni razvoj događaja vezan uz pandemiju uzrokovanu koronavirusom znatno je promijenio obrise i značajke doma kakav smo poznavali. Dom sada nije samo dom, utočište u kojemu nalazimo mir i spokoj na kraju radnog dana (barem u kontekstu zaposlenih i učenika i studenata u procesu školovanja), već je dom poprimio i mnoge druge uloge tijekom 2020. godine. Dom je postao učionica, ured, ponegdje ambulanta, teretana te poprište razonode i slobodnog vremena. Za razliku od dobrovoljnog, prisilan rad od kuće zahtijeva nov pristup istraživanju efekata koje on ima na produktivnost i mentalno zdravlje radnika (Reuschke i Felstead, 2020.). 
Uzimajući u obzir biografsku međuovisnost stvaranja doma i destinacije u kojoj se taj dom nalazi (Boccagni, 2017.), oduzimanje slobode na javnim površinama uzrokovano mjerama za suzbijanje koronavirusa može imati utjecaj i na osjećaj slobode unutar domova migranata. Kada koncept doma preoblikujemo u kontinuirano življeno iskustvo migracije (Wiles, 2008.:177), načini na koje doživljavamo dom i osjećaje vezane uz njega mogu se reflektirati na sveukupno migratorno iskustvo i proces integracije (Boccagni, 2017.:57). Takva „prenosivost“ (Boccagni, 2017.) iskustva utječe na održavanje smislenog doživljaja doma više nego fizička okruženja koja služe kao podloga za stvaranje osjećaja „kao kod kuće“. Međuovisnost javnih prostora i doma prepoznali su i Kumar i Makarova (2008.), sugerirajući kako su te granice sada "otopljene“ i arbitrarne te kako su javno i privatno u kontekstu doma migranata u kontinuiranoj interakciji te međusobno konstitutivni.

S obzirom na okolnosti koje je izazvala pandemija, u smislu socijalnog distanciranja i ograničenog kretanja na javnim površinama, mjesto koje je dosada predstavljalo zaklon i utočište ima potencijal postati kao „krilo posesivne majke, klaustrofobični prostor i [iz]gubi[ti] svoj obiteljski karakter" (Hage 1997.:3). Drugim riječima, ograničene mogućnosti kretanja, i slobode generalno, na javnim površinama mogu se reflektirati kroz osjećaj ograničene slobode i unutar doma migranata. Prethodno opisana četiri osjećaja vezana uz dom, sigurnost, familijarnost (prisnost), zajedništvo i osjećaj ili mogućnost nade (Hage, 1997.:2), sada mogu postati ozbiljno upitna ili čak ugrožena. Obiteljsko mjesto ili dom mora biti dovoljno otvoren da njegovi stanovnici mogu spoznati prilike za boljim životom: prilike za razvijanjem određenih vještina, prilike za osobnim rastom i, generalno, pristupačnost prilika za napretkom - bilo emocionalnim, socijalnim ili u formi akumulacije simboličkoga ili monetarnoga kapitala (Hage, 1997.:2). U normalnim okolnostima dom bi trebao predstavljati mogućnost promjene i transformacije (Lems, 2018.). No, kako to u posljednjih nekoliko mjeseci nije bilo potpuno ostvarivo, postavlja se pitanje kako je prisilan ostanak kod kuće utjecao ne samo na percepciju doma kao utočišta već i na mentalno zdravlje njegovih stanovnika.

U kontekstu migracija, prisilan ostanak kod kuće može uzrokovati poteškoće i prepreke u integraciji migranata. Zbog ograničene mogućnosti pristupa javnim mjestima migranti se ne mogu približiti novoj zajednici kao što bi htjeli ili mogli, što posljedično čini njihove domove patologiziranima i gubi se stvaranje „osjećaja kao kod kuće“ (Hage, 1997.). Uz nemogućnost ili smanjene opcije povratka u zemlju porijekla migranti sada imaju i ograničen pristup zajednici u zemlji odredišta, što uvelike utječe i na daljnji razvoj ovoga projekta. Zbog opisanih pretpostavki o promjenama u percepciji doma uzrokovanim globalnom pandemijom, pitanja i pristup sudionicima istraživanja zahtijevaju ponovno razmatranje te detaljnija pitanja o kontekstu doma i osjećaja sigurnosti. No, kako dom uvijek ostaje u procesu izgradnje i kako je vezan uz mnoge uspomene, sjećanja, ljude i okolnosti vezane uz nastanak pojedina doma, ljudi često žive u iluziji aspiracije prema idealnom domu (Hage, 1997::4). Stanovnici 
doma uvijek prepoznaju budući potencijal osjećaja sigurnosti i familijarnosti; koliko god se trudili postići taj finalni produkt doma i njegovu stabilnost, taj proces uvijek ostaje proces (Lems, 2018.). Upravo iz toga razloga pitanja vezana uz gradnju doma i osjećaje vezane uz njega od trenutka kad su sudionici istraživanja u njega doselili mogu dati vrlo interesantan prikaz temporalnoga razvoja toga procesa izgradnje doma i asociranih osjećaja.

\subsection{Utjecaj pandemije na transnacionalne prakse}

Kako bi se minimiziralo širenje bolesti COVID-19, pridržavanje socijalnog distanciranja - skupa ne-farmaceutskih intervencija koje zagovaraju fizičku distancu između ljudi i ograničenu ljudsku interakciju (Hartt, 2020.), postalo je globalna nužnost. Te su intervencije uključivale direktive za zatvaranjem neesencijalnih poslovanja, ograničavanjem grupnih okupljanja i poticanjem socijalne distance i kvalitetne higijene (Fenley, 2020.). Većina je ljudi tako stavljena u poziciju da prioritiziraju rad od kuće, da izbjegavaju javne površine i da poštuju sve navedene smjernice. Pandemija bolesti COVID-19 vrlo je brzo i drastično utjecala na svakodnevni život ne samo migranata već i svih ljudi na globalnoj razini. Kretanje građana diljem svijeta ograničeno je na ono „nužno“ (Fenley, 2020.). Takva se suradnja građana i javnih službi u svrhu većega dobra za cijelu zajednicu naziva i koprodukcijom (Fenley, 2020.). Specifično, suradnja tolika opsega i dosega jest forma kolektivne koprodukcije (Bovaird i sur., 2014.).

Koprodukcija je, dakle, utjecala na mnoge zajednice, tako i transnacionalne. Ograničeno je kretanje rezultiralo smanjenim opcijama za putovanje i ograničenim prisustvom na javnim mjestima, uključujući i ne-mjesta (Augé, 1995.) kao što su aerodromi. Transnacionalne su zajednice posljedično morale prilagoditi svoje planove, obiteljska okupljanja i posjete, ili čak povratak u inozemstvo, ovisno o tome $s$ koje su strane (ovdje ili ondje) pojedini akteri zatečeni u trenutku stupanja mjera na snagu. Prema Povrzanović Frykman (2010.:45), za one koji nisu migrirali, kao što su obitelji i prijatelji migranata, posjete migranata potvrđuju kontinuitet kulturnih normi koje se tiču obiteljskih i drugih društvenih odnosa. Uz ograničene prilike za povratak/ dolazak (Fenley 2020.), transnacionalne se zajednice mogu oslanjati na online platforme poput Skypea, Zooma, MS Teamsa, WhatsAppa i Messengera kako bi održavale prijateljstva i obiteljske odnose bez fizičke blizine (Walsh, 2020.). Međutim, dok je ljudima koji nisu napustili svoj dom to novitet, migrantima je to svakodnevica, koja je potencijalno samo produbila agoniju liminalnoga pozicioniranja njihova identiteta.

Trenutačna statistika o utjecaju pandemije bolesti COVID-19 na zračni promet procjenjuje da je broj putnika u međunarodnome zračnom prometu tijekom 2020. godine pao između 59\% i 62\% u usporedbi s prethodnom, 2019. godinom (International Civil Aviation Organization, 2020., posjećeno 27. 10. 2020.). Uz velik broj otkazanih letova, na postojećim se letovima nudi smanjen broj mjesta zbog obavezne socijalne 
distance. Uz smanjen broj ljudi koji svakodnevno zauzimaju jedno od tih sjedala u zračnome prostoru, međunarodne poštanske pošiljke također su bile pod neminovnim utjecajem smanjenoga protoka dobara i ljudi. $\mathrm{O}$ važnosti materijalnih praksi i njihovu protoku u transnacionalnim društvenim prostorima (vidi: Faist 2000.; Glick Schiller i sur. 1995.; Kivisto 2001.; Portes i sur. 1999.; Vertovec i Cohen 1999.) pisala je i Povrzanović Frykman (2010.), a kako su afektivni objekti i materijalna kultura upleteni u ovaj rad, objasnit ću u idućem poglavlju. Osim što materijalni predmeti imaju veliku simboličku važnost u svakodnevnim životima migranata, Povrzanović Frykman također skreće pozornost na rekonstrukciju transnacionalnih prostora: „[p] raćenje transnacionalnih putanja predmeta koji čine materijalnu potku transnacionalnih društvenih prostora može ukazati na konstrukciju prostora koji potiru važnost državnih granica i reformuliraju koncept društva, ne izjednačujući ga s državnim teritorijem“ (Povrzanović Frykman, 2010.:41). Materijalna je kultura, dakle, također jedan od važnih faktora u konstruiranju transnacionalnih prostora te ima mogućnost utjecati na svakodnevna iskustva transnacionalnih praksi.

\section{Pristup transnacionalnom terenu u doba pandemije bolesti COVID-19}

Zamišljeno kao etnografska studija, ovo doktorsko istraživanje objedinjuje nekoliko kvalitativnih metoda. Sa sudionicima istraživanja susrelo se dva puta: prvi put u svrhu polustrukturiranih intervjua, a drugi put kako bi se provela vizualna metoda temeljena na fotografiji ${ }^{5}$. Vizualna je metoda služila kako bi nadopunila podatke dobivene iz intervjua i kako bi izrazila afektivne materijalnosti transnacionalnih praksi. Tijekom intervjua i prvoga susreta sa sudionicima objasnila se vizualna metoda te što se od sudionika očekuje: zadatak je bio odabrati jedan predmet koji je usko vezan za njihovo transnacionalno i migratorno iskustvo te ga fotografirati. Taj predmet može i ne mora biti donesen iz zemlje porijekla, može biti u svakodnevnoj upotrebi ili nešto čega se rado sjete. Nakon što su ga fotografirali, drugi put kad smo se sastali razgovarali smo o tome predmetu kao i o razlozima zašto su ga odabrali. Tijekom obaju susreta provedena je i metoda promatranja sa sudjelovanjem, koja je od svih navedenih metoda bila najproblematičnija pod utjecajem mjera suzbijanja bolesti COVID-19. Sudionici su uzorkovani metodom „snježne grude“, odnosno lančanim uzorkovanjem, a ciljani broj kazivača je 40. S obzirom na to da su se metode provodile online, uzorkovanje se također proširilo u online sferu, odnosno na nalaženje sudionika putem društvenih mreža.

${ }^{5}$ Engl. photo-elicitation method 


\subsection{Implikacije i utjecaj bolesti COVID-19}

U vrijeme planiranja metodologije projekta ideja je bila intervjuirati sudionike na javnim mjestima ili, ukoliko je moguće, u njihovim domovima. Naravno, zbog financijskih i logističkih barijera u tome bi se slučaju većina (ili čak svi) sudionika nalazila na manjem teritorijalnom području u Ujedinjenom Kraljevstvu. Međutim, kako je širenje pandemije utjecalo na mnoga terenska istraživanja, te uzrokovalo komplikacije u smislu putovanja i pristupa kazivačima, sve su se metode provodile u online okruženju prilagođene danim okolnostima uz što manje preinaka i promjena u odnosu na njihovo provođenje uživo na terenu (vidi: Salmons, 2015.; Janghorban, 2014.; Beneito-Montagut, 2011.).

Kao što je Salmons (2016.:62) primijetila, samim time što će sudionici biti u svojim domovima tijekom intervjua, za svojim računalima, „možda će moći bolje i detaljnije diskutirati o privatnim temama, kao što su emocije [...] o kojima se teško otvoriti uživo". Emocije i dijeljenje osobnih i intimnih iskustava migracije od krucijalne su važnosti za ovaj rad, i tim je bitnije da sudionici budu opušteni i voljni razgovarati o toj temi. Nadalje, s obzirom na to da se većina službene komunikacije, kao što su sastanci primjerice, u nekoliko posljednjih mjeseci održava putem interneta, tehnologija i informatička pismenost sada su postali dio svakodnevice i korištenje online programa za razgovor $s$ nekime nije više strano kao što je možda bio slučaj prijašnjih godina. Štoviše, intervjui provedeni uživo mogu se percipirati kao intruzivni i nametljivi (Russell Bernard, 2006.:257), posebice ako se odvijaju u privatnim sferama kao što je nečiji dom.

Dok mnogi znanstvenici smatraju da je promatranje sa sudjelovanjem vrlo teško ili gotovo nemoguće u online intervjuima (Salmons, 2016.:62), online videosastanci i dalje pružaju prednost neposrednosti koja omogućava opažanje reakcija, gesti i ponašanja sudionika. Realnu i stvarnu sliku zamijenila je digitalna slika, koja se uz minimalne kreativne prilagodbe može i dalje koristiti kao relevantan podatak u etnografskome istraživanju. S obzirom na to da je riječ o transnacionalnim društvenim prostorima, u ovome se istraživanju može pitati sudionike da donesu pred kameru nešto što smatraju važnim za istraživanje ili čak da naprave virtualni obilazak svoga doma kako bi osoba koja intervjuira mogla steći dojam o potencijalnim simbolikama ili predmetima koji su bitni za promatranje sa sudjelovanjem. Iako je postojeća literatura o online kvalitativnom istraživanju relativno limitirana, ova situacija s pandemijom bolesti COVID-19 može ukazati na trenutačne nedostatke odnosno potencijale koje kriju online kvalitativne metode.

Online istraživanja postojala su i prije globalne pandemije, ali uglavnom potaknuta „financijskim ograničenjima, geografskom disperzijom i fizičkim granicama, što je sve utjecalo na terenska istraživanja" (Janghorban i sur., 2014.:1), dok je glavni razlog za promjenu metoda sada globalno zdravlje i sigurnost ispitanika i generalno svih građa- 
na. Istraživanje u online okruženju kao alternativa intervjuiranju uživo pruža određene prednosti, koje su u ovome pojedinom radu izražene i u njegovu teorijskom okviru. Kako se ovaj projekt oslanja na metodološki denacionalizam i multilokalnu etnografiju, koja nalazi uporište u definiranju mjesta i prostora kao arbitrarnih i konstruiranih, pandemija služi kao dodatno opravdanje i obrazloženje zašto se terenski rad ovoga projekta proširio na cijelo Ujedinjeno Kraljevstvo. Kako je prethodno objašnjeno da je u originalnome planu bilo zamišljeno da se intervjui provode u manjoj geografskoj jedinici jedne regije, uz prelazak na online metode sada je moguće intervjuirati individualne migrante koji su svoj home away from home pronašli bilo gdje u UK-u.

Razne vizualne metode također mogu biti provedene online, uz mogućnost kreativnih pristupa postojećim metodama. Campos-Delgado (2017.:184), primjerice, piše o primjeni kognitivnoga mapiranja u migracijskim istraživanjima kao o „tehnici koja omogućuje migrantima da ih se čuje i primijeti“ i kao načinu na koji možemo reprezentirati njihova putovanja. Konkretno, vizualna metoda fotografijama u ovome istraživanju mogla je biti provedena online bez velikih preinaka, uz zamolbu da sudionici pošalju svoje fotografije mailom, nakon čega je slijedio još jedan online sastanak kojem je tema bila materijalna kultura u transnacionalnim društvenim prostorima. Svi etički procesi i pristanci sudionika ostaju jednaki kao da se istraživanje provodi uživo, uz prethodno obavještenje sudionika o snimanju razgovora, bilo audio ili video (Janghorban i sur., 2014.:2).

\section{Zaključna razmatranja}

Pandemija koronavirusa promijenila je poimanje vremena i prostora kakve smo poznavali, a u ovome je radu to izraženo kroz fenomen migracije. Koncept doma, naspram poznatoga i sigurnoga, sada ima potencijal postati klaustrofobičan i utjecati na forme manifestiranja transnacionalnih društvenih praksi. Ograničeno kretanje i odsustvo iz javnih prostora te posljedičan rad od kuće uzrokovali su brige o mentalnome zdravlju svih na koje su utjecale takve mjere, ali kod migranata su posljedice dvostruke: uz dosadašnju transnacionalnu komunikaciju putem online platformi, sada se većina interakcije bazira na online komunikaciji, što zatim neizbježno utječe na njihovu mogućnost integriranja u zajednicu u zemlji odredišta.

Takve okolnosti moraju biti uključene u suvremena istraživanja o migraciji, koja će se vjerojatno, uz iznimke, morati odvijati online još neko vrijeme. U ovome radu kroz prizmu pandemije bolesti COVID-19 najveći je fokus na konceptu doma, prostora i transnacionalnih praksi kao što su materijalna kultura i njihov protok. Posljedice pandemije, iako su reflektirane i kroz metodologiju ovoga projekta i rada, mogu pružiti solidne alternative koje uz kreativna rješenja mogu dati relevantne podatke i zaključke te kao takve doprinijeti postojećoj sociološkoj literaturi. 


\section{Literatura}

1. Ahmed, S., et al. (2003). Uprootings/Regroundings: Questions of Home and Migration. Oxford, New York: Berg.

2. Al-Ali, N. and K. Koser (2002). New Approaches to Migration? Transnational Communities and the Transformation of Home. London, Routledge.

3. Anderson, B. (2016). Imagined communities: reflections on the origin and spread of nationalism / Benedict Anderson. London, London: Verso.

4. Anderson, B. (2019). New directions in migration studies: towards methodological de-nationalism. Comparative Migration Studies, 7 (1): 36.

5. Andrucki, M. J. and Dickinson, J. (2016). Rethinking Centers and Margins in Geography: Bodies, Life Course and the Performance of Transnational Space. Annals of the Association of American Geographers, 106: 203-218.

6. Appadurai, A. (1990). Disjuncture and Difference in the Global Cultural Economy. Theory, Culture, Society, 7: 295-310.

7. Appadurai, A. (1995). The production of locality, in: Fardon, R. (Ed.). Counterworks: Managing the diversity of knowledge. London and New York: Routledge.

8. Augé, M. (1995). Non-Places: Introduction to an Anthropology of Supermodernity. London and New York: Verso.

9. Bauman, Z. (2000). Liquid Modernity. Great Britain: Wiley.

10. Beech, N. (2011). Liminality and the practices of identity reconstruction. $H u$ man Relations, 64 (2): 285-302.

11. Bell, D. S. A. (2003). Mythscapes: memory, mythology, and national identity. The British Journal of Sociology, 54 (1): 63-81.

12. Beneito-Montagut, R. (2011). Ethnography goes online: towards a user-centred methodology to research interpersonal communication on the internet. Qualitative Research, 11 (6): 716-735.

13. Berdoulay, V. (1989). Place, Meaning and Discourse in French Language Geography, in: AGNEW, J. A. and Duncan, J. S. (Eds.). The Power of Place. London: Unwin Hyman.

14. Bhabha, H. K. (1994). The Location of Culture. London: Routledge.

15. Blunt, A. and R. Dowling (2006). Home. London and New York: Routledge.

16. Boccagni, P. (2017). Migration and the Search for Home. Palgrave Macmillan US.

17. Bovaird, T., et al. (2014). Activating Citizens to Participate in Collective CoProduction of Public Services. Journal of Social Policy, 44 (1): 1-23.

18. Braidotti, R. (1994). Nomadic Subjects: Embodiment and Sexual Difference in Contemporary Feminist Theory. New York: Columbia University Press.

19. Campos-Delgado, A. (2018). Counter-mapping migration: irregular migrants' stories through cognitive mapping. Mobilities, 13 (4): 488-504.

20. Chambers, R. (1994). Paradigm shift and the practice of participatory research and development. IDS working paper no. 2. Brighton, IDS.

21. Faist, T. (2000). The volume and dynamics of international migration and transnational social spaces. Oxford: Clarendon. 
22. Falzon, M. A. (2009). Multi-Sited Ethnography: Theory, Praxis and Locality in Contemporary Research. London and New York: Routledge.

23. Favell, A. (2008). Eurostars and Eurocities: free movement and mobility in an integrating Europe / Adrian Favell. Malden, Oxford: Blackwell Pub.

24. Fenley, V. M. (2020). Everyday citizenship and COVID-19: "Staying at home" while homeless. Administrative Theory \& Praxis: 1-13.

25. Gedalof, I. (2003). Taking (a) Place: Female Embodiment and the Re-grounding of Community. Uprootings/Regoundings. S. Ahmed, C. Castaneda, A. M. Fortier and M. Sheller. Oxford, New York: Berg.

26. Gennep, A. v. (1960). The rites of passage. Chicago: University of Chicago Press.

27. Glick Schiller, N., et al. (1995). From Immigrant to Transmigrant: Theorizing Transnational Migration. Anthropological Quarterly, 68 (1): 48-63.

28. Glick Schiller, N. (2008). Beyond Methodological Ethnicity: Local and Transnational Pathways of Immigrant Incorporation. Willy Brandt Series of Working Papers in International Migration and Ethnic Relations, 2: 1-36.

29. Grzymala-Kazlowska, A. and Phillimore, J. (2018). Introduction: rethinking integration. New perspectives on adaptation and settlement in the era of superdiversity. Journal of Ethnic and Migration Studies, 44 (2): 179-196.

30. Hage, G. (1997). At Home in the Entrails of the West: Multiculturalism, 'ethnic food' and migrant home-building. Home/World: Communality, identity and marginality in Sydney's West. H. Grace, G. Hage, L. Johnson, J. Langsworth and M. Symonds. Sydney: Pluto Press.

31. Hartt, M. (2020). COVID-19: a lonely pandemic. Cities \& Health: 1-3.

32. Heidegger, M. 2010. Being and Time. Albany, New York: State University of New York.

33. International Civil Aviation Organization (2020). Economic Impacts of COVID-19 on Civil Aviation. https://www.icao.int/sustainability/Pages/EconomicImpacts-of-COVID-19.aspx. (Pregledano 27.10. 2020.)

34. Janghorban, R., et al. (2014). Skype interviewing: The new generation of online synchronous interview in qualitative research. International Journal of Qualitative Studies on Health and Well-Being, 9 (1).

35. Kivisto, P. (2001). Theorizing transnational immigration: a critical review of current efforts. Ethnic and Racial Studies, 24 (4): 549-577.

36. Kumar, K. and Makarova, E. (2008). The Portable Home: The Domestication of Public Space. Sociological Theory, 26 (4): 324-343.

37. Lefebvre, H. (1991). The Production of Space. Oxford: Blackwell.

38. Lems, A. (2016). Placing Displacement: Place-making in a World of Movement. Ethnos, 81 (2): 315-337.

39. Lems, A. (2018). Being-Here: Placemaking in a World of Movement. Berghahn Books.

40. Low, S. (2017). Spatializing Culture: The Ethnography of Space and Place. Oxford and New York: Routledge. 
41. Massey, D. B. (2005). For space / Doreen Massey. London: SAGE.

42. Mouffe, C. (1994). For a politics of nomadic identity. Traveller's Tales: Narratives of Home and Displacement. G. Robertson, M. Mash, L. Tickner et al. London and New York: Routledge.

43. Palmberger, M. and Tošić, J. (2017). Memories on the Move: Experiencing Mobility, Rethinking the Past. London: Palgrave Macmillan UK.

44. Portes, A., et al. (1999). The study of transnationalism: pitfalls and promise of an emergent research field. Ethnic and Racial Studies, 22 (2): 217-237.

45. Povrzanović Frykman, M. (2010). Materijalne prakse bivanja i pripadanja u transnacionalnim drustvenim prostorima. Studia Ethnologica Croatica, 22: 39-60.

46. Reuschke, D. and Felstead, A. (2020). Changing workplace geographies in the COVID-19 crisis. Dialogues in Human Geography, 10 (2): 208-212.

47. Robertson, G., et al. (1994). Travellers' Tales: Narratives of Home and Displacement. London and New York: Routledge.

48. Rodman, M. C. (1992). Empowering Place: Multilocality and Multivocality. American Anthropologist, 94: 640-656.

49. Russell Bernard, H. (2006). Research Methods in Anthropology: Qualitative and Quantitative Approaches. United States of America: Altamira Press.

50. Said, E. W. (1995). Orientalism / Edward W. Said. London, London: Penguin.

51. Salmons, J. (2015). Qualitative Online Interviews: Strategies, Design and Skills. United States of America: Sage Publications, Inc.

52. Sarup, M. (1994). Home and Identity. Traveller's Tales: Naratives of Home and Displacement. G. Robertson, M. Mash, L. Tickner et al. London and New York: Routledge.

53. Smith, M. P. (2005). Power in Place/Places of Power: Contextualizing Transnational Research. City and Society, 17: 5-34.

54. Szakolczai, A. (2014). Living Permanent Liminality: The Recent Transition Experience in Ireland. Irish Journal of Sociology, 22 (1): 28-50.

55. Thomassen, B. (2014). Liminality and the Modern: Living Through the In-Between. Farnham, UK; Burlington, USA, Ashgate Publishing Limited.

56. Tilley, C. (2006). Introduction: Identity, Place, Landscape and Heritage. Journal of Material Culture, 11: 7-32.

57. Turner, V. (1970). The Forest of Symbols: Aspects of Ndembu Ritual. Ithaca, New York: Cornell University Press.

58. Urry, J. (2000). Sociology Beyond Societies: Mobilities for the Twenty-first Century. London and New York, Routledge.

59. Vertovec, S. and Cohen, R. (1999). Migration, Diasporas, and Transnationalism. Cheltenham. UK: Elgar Reference Collection.

60. Vertovec, S. (2007). Super-diversity and its implications. Ethnic and Racial Studies, 30 (6): 1024-1054.

61. Walsh, K. (2020). A response from home: Intimate subjectivities and (im)mobilities during COVID-19. Dialogues in Human Geography: 2043820620937607. 
62. Wiles, J. (2008). Sense of home in a transnational social space: New Zealanders in London. Global Networks, 8 (1): 116-137.

63. Woodward, I. (2007). Understanding Material Culture. Los Angeles, London, New Delhi, Singapore: SAGE Publications.

64. Yeoh, B. S. A., et al. (2005). Introduction. Asian migrations: Sojourning, displacement, homecoming and other travels. B. S. A. S. Yeoh, H. H., N. Piper and B. P. Lorente. Singapore, Asia Research Institute, National University of Singapore: 1-6. 
Pregledni rad

\title{
Liminal Identities and Transnational Spaces in the Time of the COVID-19 Disease Pandemic
}

\author{
Franka Zlatić \\ University of Nottingham, School of Sociology and Social Policy, UK \\ e-mail:franka.zlatic@nottingham.ac.uk
}

\begin{abstract}
This article summarizes my doctoral project, which investigates the way first generation individual migrants balance their simultaneous presence of both home and host country. The theoretical frame of the project draws from methodological de-nationalism and alternative readings of concepts of place and space, which are described in the first part of the article. The second part focuses on explaining how COVID-19 affected the methodology of the project, describing all the methods and the way of their application in an online setting. Finally, the article describes online alternatives to existing qualitative methods in migration related research and its potential benefits.
\end{abstract}

Key words: Transnationalism, liminality, multi-sited ethnography, migration, transnational social spaces, COVID-19. 